\title{
DISLOCATION OF THE HIP IN YOUNG RATS PRODUCED EXPERIMENTALLY BY PROLONGED EXTENSION
}

\author{
S. Sijbrandiu, Almelo, The Netherlands
}

From the Department of Anatomy and Embryology, State University, Groningen

The etiology of congenital dislocation of the hip is still the subject of much discussion. Genetic growth disturbance, intra-uterine and post-natal mechanical influences are considered as possible factors. According to Hass (1951) typical congenital dislocation of the hip is not primarily a congenital disease. It develops secondarily during the first and second years of life. Only the disposition to dislocation is congenital, namely a disturbance of ossification in the region of the hip. The flatness of the acetabular roof is the principal anatomical feature, but the genetic growth disturbance also extends to the upper end of the femur. It is of interest to report experiments on young rats in which it was possible to produce dislocation of the hip by mechanical influences alone.

\section{MATERIAL AND METHODS}

Sixty three-week-old male rats were used. The right hind leg was splinted in a glass cylinder (Fig. 1). The foot was attached by adhesive tape to a metal rod at the end of the glass cylinder. During the experiments the cylinders were changed from time to time to avoid pressure on the growing leg. The animals were able to move around freely on three legs. In some animals splintage was not continuous because the cylinders slipped off.

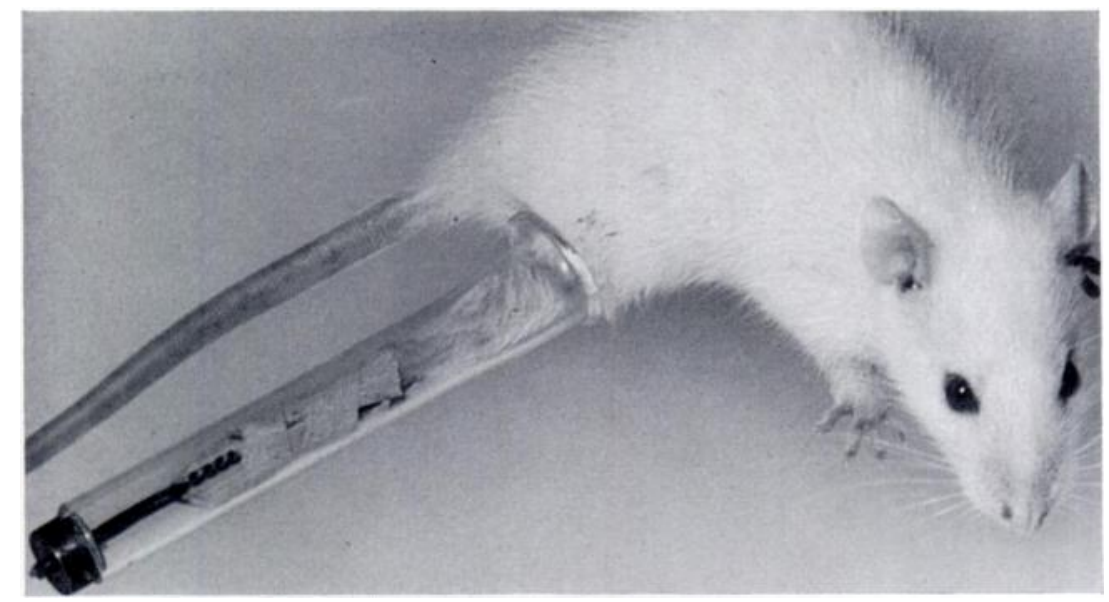

FIG. 1

Showing the method and position of splintage.

In the normal rat the hips and knees are always flexed and the ankle is in extreme dorsiflexion. After application of the cylinders the knee and ankles were immobilised in a position of nearly full extension. The hip was not completely immobilised but was much more extended than normal. Radiographs of both hips were taken in extension under anaesthesia at intervals of four to six weeks. After two and a half months of splinting the rats were killed and radiographs taken again. Both hips were then dissected and photographed. 


\section{RESULTS}

Dislocation of the hip occurred in the immobilised limbs in which splintage was continuous. A radiograph taken after ten weeks of splinting showed dislocation and reduction in size of the femoral head and the neck of the femur (Fig. 2). The empty acetabulum was flattened and the acetabular roof underdeveloped. The knees and ankles appeared to be normal. It is likely that dislocation took place within four to five weeks of splinting and that changes in the bony elements of the hip joint developed within this period of time. In hips that were not continuously splinted subluxation occurred but not dislocation (Fig. 3). The acetabular roof was quite flat and the femoral head underdeveloped.

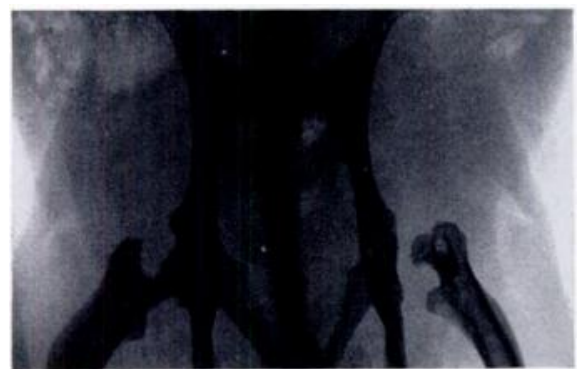

FIG. 2

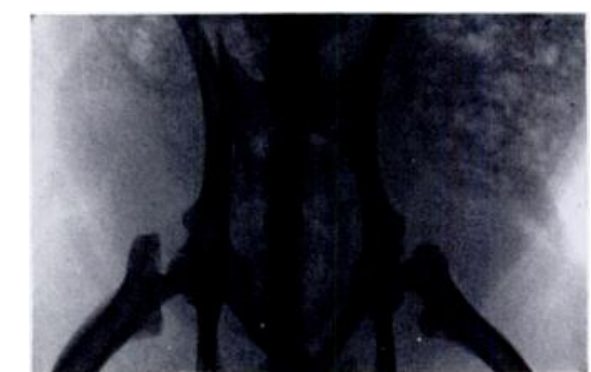

Fig. 3

Figure 2-Radiograph of the right hind leg after splintage for ten weeks showing dislocation of the right hip. The femoral head is smaller than normal; the empty acetabulum is flattened and the acetabular roof is underdeveloped. Figure 3-Radiograph of the right hind leg which was not continuously splinted. Subluxation occurred and a reduction in the size of the femoral head.

Necropsy specimens of rats with complete dislocation showed thickening of the capsule. The acetabular surface was irregular and had lost its smoothness (Fig. 4). In the untreated left hips no changes were found. Splinting did not have much influence on the pelvic musculature. There was only slight atrophy of the muscles of the splinted leg and some underdevelopment of the foot (Fig. 5). The angle of anteversion was, in most cases, 10 to 20 degrees greater than on the control side (Fig. 6).

\section{DISCUSSION}

The experiments show that in the young rat dislocation of the hip and underdevelopment of the acetabulum and the proximal end of the femur can be produced by partial immobilisation of the hip in extension. The dislocation and the associated abnormalities of the joint resemble congenital dislocation in man. Interrupted splintage caused a condition similar to that of subluxation in the human.

Several authors have assumed that in man extension of the hip plays an important part in the development of congenital dislocation. Le Damany (1923) concluded that in the presence of anteversion as a developmental fault, dislocation develops when the flexed hips are brought into extension in the first six months of life. Similarly, Erlacher (1963) stated that extension of the infant's hips by the mother or the midwife soon after birth is one of the most harmful "attacks" on the stability of the hip disposed to dislocation, as extension pushes the femoral head upwards and backwards. If no harm is to be caused, extension of the legs must be allowed to develop by active movements of the child. Other authors concluded, on the basis of clinical studies, that post-natal extension of the hip increases its instability (Harrenstein 1924, Somerville 1953).

Etiological factors of a quite different kind have been stressed by Wilkinson (1963), who observed that breech malposition and hormonal joint laxity can produce posterior subluxation in the hips of young rabbits. Progressive acetabular dysplasia and deformities of the femoral head and neck, similar to those observed in the reported experiments, have been 


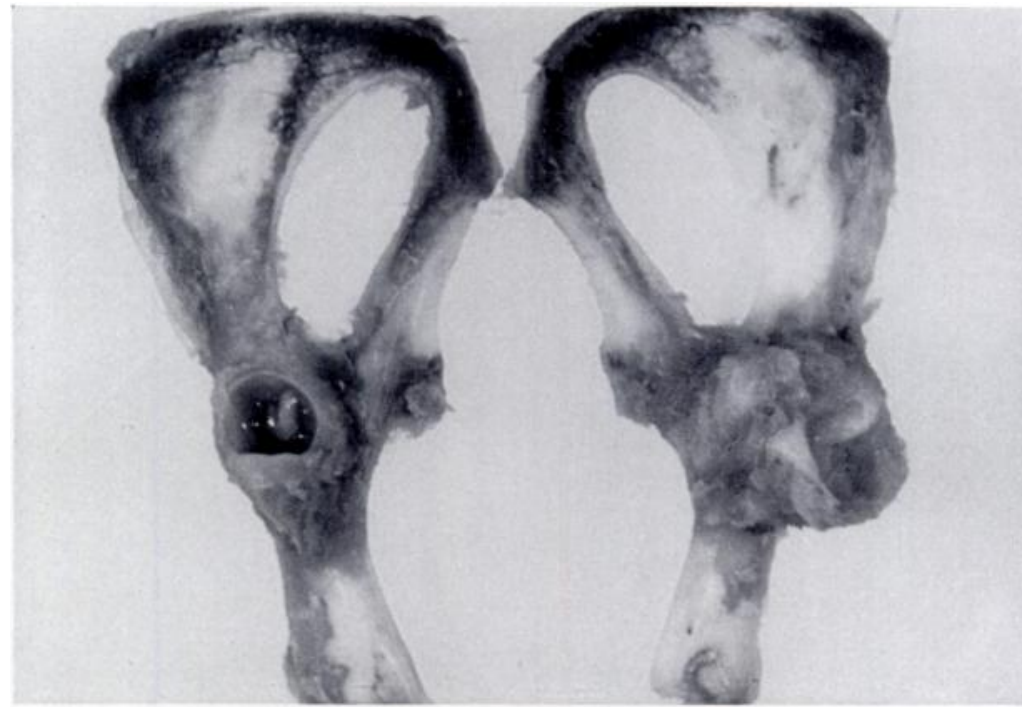

Fig. 4

Necropsy photograph of the acetabulae of a rat which was continuously splinted showing that the acetabular surface is irregular and has lost its smoothness and the joint capsule is thickened.

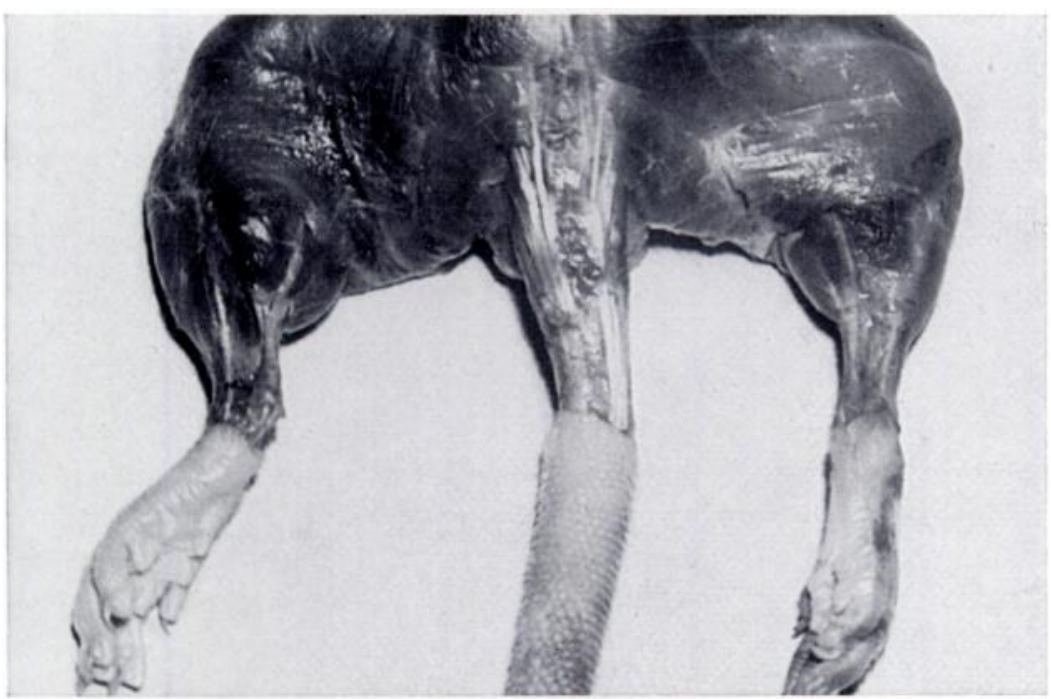

Fig. 5

The legs of a three-month-old rat after continuous splinting showing atrophy of the muscles and underdevelopment of the foot.

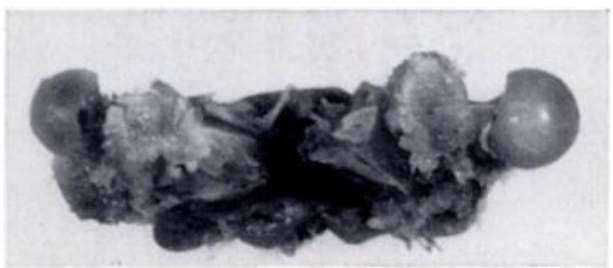

Fig. 6

Necropsy photograph of a rat's femur which was continuously splinted showing increased anteversion of the femoral neck.

THE JOURNAL OF BONE AND JOINT SURGERY 
found in investigations in which traumatic dislocation was produced in young laboratory animals by operation or pressure (Smith, Ireton and Coleman 1958; Langenskiöld, Sarpio and Michelsson 1962). The observations of Massie (1956) also suggest that anatomical anomalies of the hip area may be secondary to dislocation.

My observations seem to support the view that extension of the hip soon after birth is of importance in the pathogenesis of congenital dislocation of the hip in man. Dislocation was produced in conditions in which genetic, intra-uterine and endocrine factors could be excluded.

However, it is realised that in the development of congenital dislocation in man, nonmechanical factors must also be involved. This is apparent from the higher incidence of the condition in girls, the difference in familial, racial and geographical distribution and a predominantly unilateral incidence.

\section{SUMMARY}

1. Dislocation and subluxation of the hip has been produced in young rats by application of splints reaching from the hip to the foot, bringing the hip into extension.

2. Progressive acetabular dysplasia and anatomical abnormalities of the head and neck of the femur occurred.

3. Results of the experiments suggest that post-natal extension of the hip is of importance in the pathogenesis of congenital dislocation of the hip in man.

\section{REFERENCES}

Erlacher, P. J. (1963): Zum Prinzip der Frhubehandlung der Huftdysplasie. Fortbildungskurs 9 Kongres der Societe Internationale de Chirurgie Orthopedique et de Traumatologie, Wien: Romayor.

Harrenstein, R. J. (1924): A Critical Period in the Development of the Hip Joint (and its Significance in the Origin of Congenital Dislocation) (in Dutch). Nederlands Tijdschrift voor Geneeskunde, 68, 2328.

Hass, J. (1951): Congenital Dislocation of the Hip. Springfield: Charles C. Thomas.

Langenskiöld, A., Sarpio, O., and Michelsson, J.-E. (1962): Experimental Dislocation of the Hip in the Rabbit. Journal of Bone and Joint Surgery, 44-B, 209.

Le Damany, P. (1923): La luxation congénitale de la hanche. Paris: Ernest Flammarion.

Massie, W. K. (1956): Congenital Dislocation of the Hip. Its Causes and Effects. Clinical Orthopaedics, 8, 103.

Smith, W. S., Ireton, R. J., and Coleman, C. R. (1958): Sequelae of Experimental Dislocation of a WeightBearing Ball-and-Socket Joint in a Young Growing Animal. Journal of Bone and Joint Surgery, 40-A, 1121.

Somerville, E. W. (1953): Development of Congenital Dislocation of the Hip. Journal of Bone and Joint Surgery, 35-B, 568.

Wilkinson, J. A. (1963): Prime Factors in the Etiology of Congenital Dislocation of the Hip. Journal of Bone and Joint Surgery, 45-B, 268. 